\title{
Six years' experience of prophylactic oral vitamin $\mathrm{K}$
}

Unni Wariyar, Stephen Hilton, Julie Pagan, Win Tin, Edmund Hey

\begin{abstract}
Aims-The ability of oral vitamin $\mathrm{K}$ to eliminate all risk of vitamin $\mathrm{K}$ deficiency bleeding during the first three months of life was studied.

Methods-Babies $(n=182000)$ in the north of England judged well enough to be offered milk within 12 hours of birth were given $1 \mathrm{mg}$ of phytomenadione (vitamin $\mathbf{K}_{1}$ ) suspended in a medium chain triglyceride oil by mouth at delivery between 1993 and 1998. The parents of those who were breastfed were given a further three doses to give to the baby once every two weeks after discharge.

Results-Four breastfed babies developed late vitamin $\mathrm{K}$ deficiency bleeding. In two, staff failed to follow policy guidelines, and in two there was undiagnosed $\alpha_{1}$ antitrypsin deficiency. Audit suggested that $\mathbf{9 3 \%}$ of breastfed babies had all four doses, as advised.

Conclusions-An oral product that parents can administer themselves would be popular if licensed, but the total dose offered may need to be more than in this study if babies with undiagnosed liver disease are to be protected.
\end{abstract}

(Arch Dis Child Fetal Neonatal Ed 2000;82:F64-F68)

Keywords: vitamin $\mathrm{K}$ prophylaxis; bleeding; breast feeding

With the recognition that vitamin $\mathrm{K}$ deficiency can cause postneonatal as well as neonatal bleeding, ${ }^{12}$ there has been increased interest in the relative efficacy of oral and intramuscular prophylaxis. Countries with a uniform policy have been able to evaluate their practice, but divergent practice ${ }^{3}$ has made any comparable exercise impracticable in most of the UK since 1992.

A uniform policy of oral vitamin $\mathrm{K}$ prophylaxis was, however, adopted by 17 of the 18 consultant led maternity units, by the four GP maternity units, and by all the community midwives working in the north of England in 1993. The only other maternity unit adopted a slightly different policy of oral prophylaxis (see below). We now report on the efficacy of these policies in preventing serious vitamin $\mathrm{K}$ deficiency bleeding in the first three months of life among all the babies born in the study area between 1993 and 1998 inclusive.

\section{Methods}

All babies were to be given $1 \mathrm{mg}$ of an oral preparation of phytomenadione (vitamin $\mathrm{K}_{1}$ ) at birth. In a small group of babies (those born to mothers receiving warfarin, rifampicin, or anticonvulsant medication, and those not judged to be well enough to be offered milk in the first 12 hours of life) a $0.1 \mathrm{mg} / \mathrm{kg}$ dose of intramuscular phytomenadione was recommended immediately after delivery. The oral preparation was Orakay, which contains a medium chain triglyceride obtained from fractionated coconut oil (miglyol 812). The intramuscular preparation was Konakion, which contains phenol, propylene glycol, and polyoxyl 35 castor oil (a non-ionic surfactant). Irrespective of their treatment at birth, it was further recommended that the parents of all breastfed babies should then be given three $1 \mathrm{mg}$ capsules of Orakay, and told to give their baby the contents of one capsule at fortnightly intervals after discharge.

One unit followed a slightly different policy, giving $2 \mathrm{mg}$ (2 drops) of an oral Konakion product at birth, and again at discharge to all babies, whether breastfed or not. This product, which is widely licensed for use in Europe but not in the UK, contains methyl and propyl hydroxybenzoate, benzoic acid and polyoxyl 35 castor oil. Any baby judged not well enough to be offered milk in the first 12 hours of life received $0.1 \mathrm{mg} / \mathrm{kg}$ of intramuscular Konakion as in other units. There were 21679 live births in this unit during the study period. None developed either early or late symptomatic vitamin $\mathrm{K}$ deficiency. The births from this unit have been excluded from the findings presented in the remainder of this report.

No attempt was made to impose a uniform strategy as to the way parents were informed of the issues relating to vitamin prophylaxis. Some units gave out written information in the antenatal period while others only raised the issue formally after delivery. Many, but not all, offered written information.

A retrospective audit of special care and postnatal ward case notes in each unit was undertaken to estimate the proportion of babies receiving intramuscular prophylaxis at birth, and to estimate the proportion who failed to receive any prophylaxis. While it was possible to determine, from the case notes, whether the mothers had been prescribed a further supply of vitamin $\mathrm{K}$ for use after discharge, this does not guarantee that the family actually received it.

Two parental surveys were undertaken therefore, to establish whether parents had been given a supply of vitamin $\mathrm{K}$ at discharge. Parents were also asked, at the same time, whether they understood why prophylaxis was recommended, whether they had any concerns over what they had been advised, and whether 


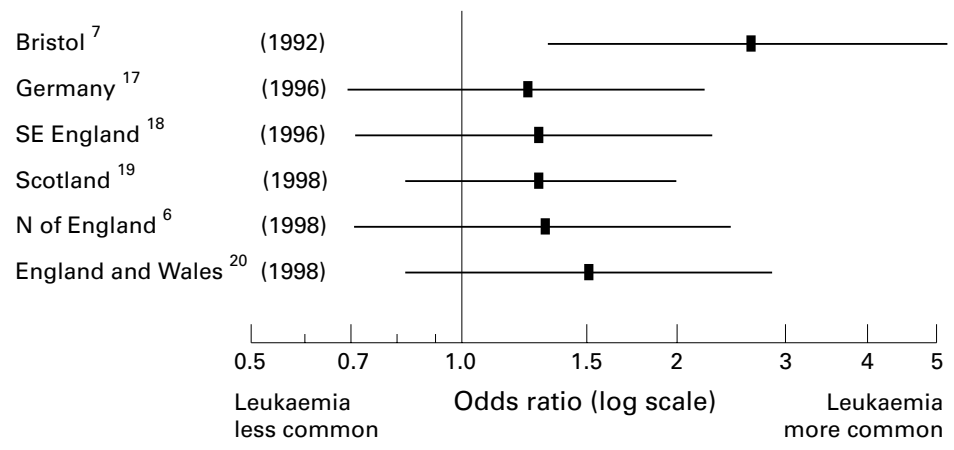

Figure 1 Odds ratios and 95\% CI for all cases of leukaemia in children under 15 given intramuscular vitamin $K$ compared with those given no treatment in all six published case-control studies where children have been matched for date and place of birth. The previously unpublished OR for the 148 babies in the North of England study born in units where clear documentation made "imputation" of treatment from a knowledge of hospital policy unnecessary is 1.32 (95\% CI: 0.71-2.47). There were 47 discordant case sets.

they had given the further doses as recommended. A sample of breast feeding mothers were seen and questioned by local health visitors in Northumberland 6-9 weeks after delivery. A second group of mothers from South Cleveland who were breast feeding at discharge were later sent a short attitudinal questionnaire. Both questionnaires approached the issue of compliance obliquely by asking whether the parents had had any problems giving the additional doses as recommended. All paediatricians in the Northern Region were contacted at intervals and asked if

No prophylaxis

$\begin{array}{lll}\text { Japan }^{25} & 1978-80 & 424 / 4930000 \\ \text { Japan }^{25} & 1981-85 & 484 / 6740000 \\ \text { UK }^{26} & 1988-89 & 10 / 220000 \\ \text { Germany }^{27} & 1988 & 10 / 138750\end{array}$

1 or $2 \mathrm{mg}$ by mouth at birth

$\begin{array}{lll}\text { Switzerland }^{28} & 1986-87 & 7 / 109000 \\ \text { UK }^{26} & 1988-89 & 7 / 49300 \\ \text { Sweden }^{29} & 1987-89 & 17 / 332686 \\ \text { Denmark }^{30} & 1990-92 & 6 / 134500\end{array}$

$1 \mathrm{mg}$ by mouth at birth, and at 1 and 3-5 weeks

$$
\begin{array}{lll}
\text { Australia }^{31} & 1993-98 & 2 / 101700 \\
\text { Germany }^{31} & 1993-94 & 22 / 1200000
\end{array}
$$

$2 \mathrm{mg}$ by mouth at 1 and 4 days (mixed micelles)

$$
\text { Switzerland }^{31} \quad 1995 \quad 1 / 83000
$$

$1 \mathrm{mg}$ by mouth at birth, and at 2,4 and 6 weeks

$$
\text { North of England 1993-98 2/193472 }
$$

$1 \mathrm{mg}$ at birth and $25 \mathrm{~g}$ by mouth daily for 3 months

$$
\text { Netherlands }^{31} \quad \text { 1993-94 3/439000 }
$$

$2 \mathrm{mg}$ at birth and $1 \mathrm{mg}$ by mouth weekly for 3 months

$$
\text { Denmark }^{30} \quad \text { 1993-98 0/357000 }
$$

$1 \mathrm{mg}$ intramuscularly at birth

$$
\begin{array}{lll}
\text { UK }^{26} & 1988-89 & 0 / 945000 \\
\text { Australia }^{31} & 1993-98 & 1 / 779477
\end{array}
$$

they had encountered any possible cases of early or late vitamin $\mathrm{K}$ deficiency bleeding. The notes of any cases identified were then reviewed in detail and the case classified using the same internationally agreed criteria as in other epidemiological studies. ${ }^{4}$ Returns were also cross checked against those that had been made monthly to the British Paediatric Surveillance Unit in 1993-4. No discrepancies were found. All deaths in the first year of life were checked against returns both to the Office of National Statistics and, separately, to the region's long running Survey of Perinatal and Infant Mortality, to make sure that no death that could have been due to vitamin $\mathrm{K}$ deficiency bleeding went unrecognised. Significant ascertainment failure due to movement out of the study area can be discounted because other studies have shown that this affects less than $4 \%$ of all families in the first two years of life. ${ }^{56}$

\section{Results}

A total of 193472 babies were born in the study units between 1993 and 1998 inclusive. Audit of a sample of 1400 case notes found that only about $6 \%$ (95\% confidence intervals $4.8-$ $7.4 \%$ ) of babies received intramuscular prophylaxis. There were no cases in the sample where prophylaxis was not prescribed at birth, but the sample contained the notes of two

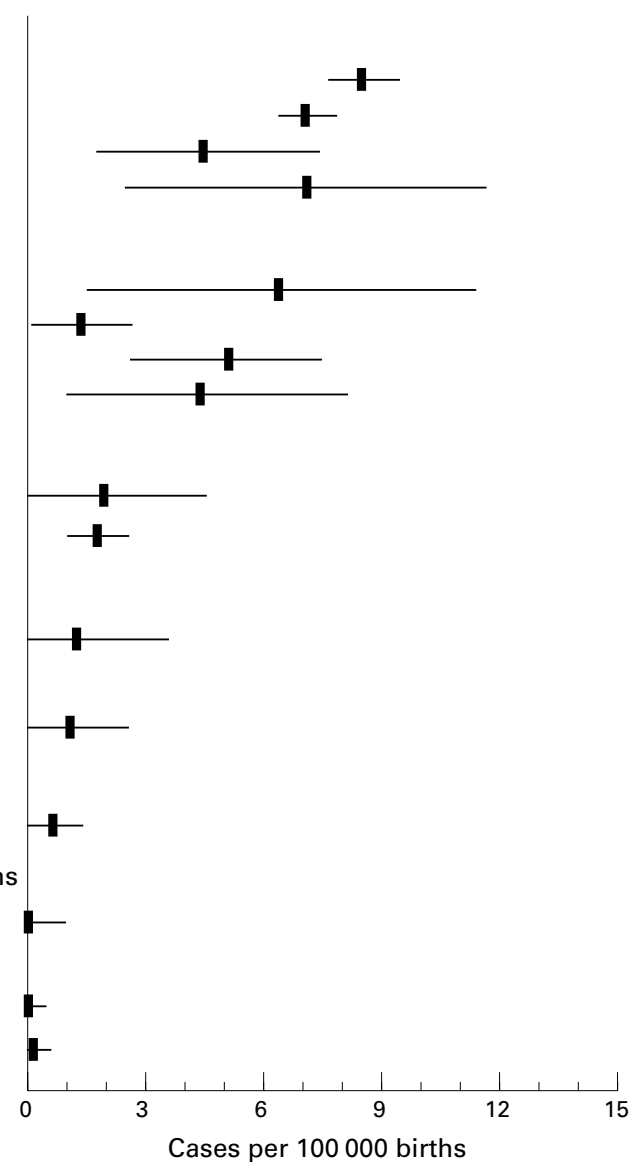

Figure 2 Incidence of late vitamin $K$ deficiency bleeding in various population studies, excluding cases where bleeding occurred because prophylactic vitamin K was not given, as recommended, with 95\% CI. Konakion was used in all studies except the 1995 Swiss study, where Konakion MM was used, and the current study, where Orakay was used. A small, but poorly defined minority of "ill" babies received intramuscular prophylaxis in all the studies of multidose oral prophylaxis. 
babies $(0.1 \%)$ whose mothers refused either intramuscular or oral prophylaxis.

None of the estimated 182000 babies treated with Orakay developed any sign suggestive of vitamin $\mathrm{K}$ deficiency bleeding in the first seven days of life. Four documented cases of late vitamin $\mathrm{K}$ deficiency bleeding occurred to babies born during this time. All had been fully breastfed. Two of these babies bled despite receiving fortnightly oral prophylaxis and were later found to have $\alpha_{1}$ - antitrypsin deficiency. One was admitted with haematuria, bruising, and continuing low grade jaundice at 25 days; the other was already under investigation for continued jaundice when admitted with irritability and vomiting at 40 days. The following day oozing was seen from venepuncture sites and there were signs of raised intracranial pressure as a result of a posterior fossa bleed. Both babies made a complete recovery, although the second had transient posthaemorrhagic hydrocephalus.

Two otherwise healthy breastfed babies developed late vitamin $\mathrm{K}$ deficiency bleeding because unit staff did not give the parents any capsules, nor recommend further prophylaxis, at discharge. One baby, who received only a single prophylactic dose of oral vitamin $\mathrm{K}$ at birth, was admitted with blood streaked vomiting at 46 days. A second, who never received any prophylaxis, was admitted with irritability and vomiting at 39 days. Both had seizures within a day of admission. Signs of raised intracranial pressure developed, and scans showed evidence of intracerebral bleeding. Bleeding from venepuncture sites led to hypoprothrombinaemia being diagnosed, which responded promptly to intramuscular vitamin $\mathrm{K}$. The second had also bled during circumcision, but there had been no other "warning bleeds" before admission. One made a complete recovery and the other was making normal developmental progress at 21 months, although there were signs of residual epilepsy.

Seven hundred and fifty breast feeding mothers from one centre were sent a questionnaire, and a further 173 randomly selected breast feeding mothers delivering in any of five centres were approached by health visitors, 6-9 weeks after delivery. Four hundred and fifty eight mothers $(61 \%)$ responded to the postal survey and all the 173 mothers approached by health visitors responded. All responders in both samples confirmed that they had been given further supplies of vitamin $\mathrm{K}$ to administer to their babies. Parents seemed well informed of the reasons for prophylaxis, and happy to have been given the responsibility for giving their baby the recommended vitamin supplement. Although only $61 \%$ of the mothers responded to the postal questionnaire, the proportion of those still breast feeding who had given all the further doses, as advised, was the same as in the smaller study where reporting bias was eliminated by getting the health visitor to speak to each family. Data from both studies suggested that $93 \%$ of the babies still being breastfed had had all four doses as recommended, and that $98 \%$ had had at least three doses.

\section{Discussion}

The concern generated by the 1992 report, suggesting that intramuscular vitamin $\mathrm{K}$ might be associated with a greater incidence of childhood leukaemia, ${ }^{7}$ has generated much uncertainty. The Chief Medical Officer made no specific recommendation, ${ }^{8}$ even though guidance on neonatal vitamin needs had been included in earlier departmental reports. ${ }^{9}$ The former British Paediatric Association decided to recommend the use of a licensed product by an unlicensed route (giving the intramuscular preparation by mouth), ${ }^{10}$ but the Health Visitors' Association expressed reluctance, on legal advice, to support such a move, ${ }^{11}$ while Roche (the drug company involved) did not apply to license the oral formulation they had on sale in Europe for use in the UK. The Department of Health could have developed a nutritional supplement (similar to the noncommercial multi-vitamin drops that have been available from child health clinics to prevent rickets since 1940), ${ }^{12}{ }^{13}$ but did not. Roche have since been given a license for a new, concentrated, and more expensive micellar product, suitable for intravenous, intramuscular, or oral use, ${ }^{14}$ but no good, large scale, population based study of this product's ability to prevent late vitamin $\mathrm{K}$ deficiency bleeding has yet appeared, and the product only has a license for oral use in babies of 36 weeks of gestation or more.

Five replications of the 1992 case control study, suggesting that intramuscular prophylaxis could be carcinogenic, ${ }^{7}$ have since appeared, but the situation is still unclear, ${ }^{15}$ and saying that there is no proof of any link is not the same thing as proving that no link exists. While none of the new studies taken in isolation has shown a difference in the incidence of childhood leukaemia that is large enough to be significant, the proportion subsequently developing leukaemia was higher among those given intramuscular vitamin $\mathrm{K}$ at birth in all the studies where cases and controls were matched for both date and place of birth. The anonymous expert working party convened by the Department of Health, the Medicines Control Agency, and the Committee on Safety of Medicines in October 1997 concluded that "the findings of epidemiological studies, some of which suggest the possibility of an increased risk [of leukaemia], are inconsistent," ${ }^{\prime 16}$ but that is not how many will interpret the data. In fact, they all suggest an increased risk (fig 1), and the magnitude of the suggested increase is remarkably consistent.

Unfortunately, no randomised trial was ever attempted before universal prophylaxis became commonplace. Hospitals with a history of selective prophylaxis usually targeted babies having an operative delivery (on the dubious assumption that these were the babies most at risk of "birth trauma"). ${ }^{21}$ As a result, it is impossible to tell whether the apparent 20$50 \%$ increase in the incidence of subsequent leukaemia was actually caused by the treatment given at birth, or whether some other factor, which rendered these babies more liable to 
operative delivery, also rendered them more liable to develop leukaemia later in childhood. ${ }^{20}$

The continuing uncertainty will be difficult to resolve: case note destruction makes information on past practice increasingly difficult to obtain, ${ }^{6} 1820$ and few babies born now avoid some form of prophylaxis. ${ }^{3}$ Furthermore, because childhood cancer is relatively common, while life threatening vitamin $\mathrm{K}$ deficiency bleeding is now very rare, even a $10 \%$ increase in the incidence of childhood cancer, were it causally related, might result in a policy of universal intramuscular prophylaxis doing more harm than good. ${ }^{20} \mathrm{~A}$ randomised trial would be needed to answer this question unequivocally but, to rule out a $10 \%$ difference in the incidence of subsequent cancer, it would have to be very large indeed. Many clinicians would, therefore, support a policy of oral prophylaxis if a regimen could be found that abolishes late symptomatic deficiency as effectively as the long established policy of giving all babies intramuscular vitamin $\mathrm{K}$ at birth.

Those who first introduced routine prophylaxis 60 years ago gave vitamin $\mathrm{K}$ by mouth. ${ }^{22}$ This route was also endorsed by the American Academy of Pediatrics, ${ }^{23}$ and encouraged by those who believed that nobody wants an injection on their birthday! ${ }^{24}$ Indeed it would seem that intramuscular treatment only became the norm in the UK and North America because no commercial company made an oral product available. However, studies have now shown that although a single $1 \mathrm{mg}$ oral dose of the standard preparation at birth is enough to prevent symptomatic deficiency in the first 2 weeks of life, it does little to reduce the incidence of subsequent vitamin $\mathrm{K}$ deficiency bleeding (fig 2). Late bleeding is reduced by three $1 \mathrm{mg}$ doses, but is still seen even in some babies without liver disease. Four well spaced doses abolished all symptomatic deficiency in healthy babies in the present study, but was not enough for babies with unrecognised liver disease. A weekly dose does seem to offer complete protection. ${ }^{30}$ The relative efficacy of the various policies can only be assessed with limited precision because late symptomatic deficiency is only seen in breastfed babies, and the proportion so fed was not the same in each study.

Giving a modest oral dose at regular intervals seems more effective than giving just one or two large doses before discharge - an observation consistent with the suggestion that intramuscular prophylaxis may work, not because it bypasses poor intestinal uptake (a problem the new micellar product was designed to address), but because it establishes a slowly released "depot" of vitamin $\mathrm{K}$ within muscle tissue. ${ }^{32}$ Two $2 \mathrm{mg}$ oral doses of the new micellar product are certainly not enough to abolish all risk of late symptomatic deficiency, ${ }^{31}{ }^{33}$ although further postdischarge doses may achieve this. ${ }^{34}$ However, because this product is better absorbed when taken by mouth, ${ }^{35}$ a $2 \mathrm{mg}$ dose produces a transient peak serum concentration similar to that associated with the $1 \mathrm{mg}$ injection and about 100 times the plasma con- centration of the vitamin $\mathrm{K}$ sufficient adult. ${ }^{36}$ Policies that require a health care professional to administer every dose have not always worked well in practice, ${ }^{31} 3738$ but devolving responsibility to the parents worked well in the present study. While mothers may have overstated the consistency with which they gave the further oral doses as advised, the only healthy babies for whom the present regional policy failed were the two babies where health professionals, rather than parents, failed to follow local policy guidelines.

A small daily supplement has attractions, and would mimic what happens to the bottle fed baby (because all formula milks are artificially fortified). Late symptomatic vitamin $\mathrm{K}$ deficiency is not seen in these babies, and there is no evidence that they are at increased risk of childhood cancer. ${ }^{39}$ Unfortunately no low dose formulation is currently available in the UK. Daily prophylaxis has worked well in the Netherlands, ${ }^{31}$ but the $25 \mu \mathrm{g}$ dose does not seem to be enough for some babies with occult liver disease (fig 2). ${ }^{40}$ Oral prophylaxis is at risk of being discredited ${ }^{41}$ merely because the dose and, more importantly, dose frequency has not yet been optimised. Maternal prophylaxis during breast feeding provides an alternative, rather more complex, strategy. ${ }^{42-44}$

Certainly, if there is to be any genuine commitment to the prevention of vitamin $\mathrm{K}$ deficiency bleeding, and to offering families genuine choice, hospitals need to make sustained oral prophylaxis available, and like intramuscular prophylaxis, it should also be free of charge.

We are grateful to our colleagues in the Northern Neonatal Network for their collaboration, without which this study would not have been possible, to Drs McNinch and Tripp, and the not have been possible, to Drs McNinch and Tripp, and the
British Paediatric Surveillance Unit for cross validating the British Paediatric Surveillance Unit for cross validating the
reported episodes of vitamin K deficiency bleeding in 1993 and 1994 , to Dr Nørgaard Hansen for information on symptomatic vitamin K deficiency bleeding in Denmark ${ }^{30}$ in 1996-8, and to Dr Laughnan and the Australian Paediatric Surveillance Unit or information from the study of all births in Victoria and New South Wales in 1993-98 which modifies and augments the information published in $1997 .{ }^{31}$ Deborah Magor set up the postal study designed to assess attitudes to oral prophylaxis while working as a student pharmacy technician in Middlesbrough. Health visitors in Northumberland made the other parental interview study possible.

1 McNinch AW, L'Orme R, Tripp JH. Haemorrhagic disease of the newborn returns. Lancet 1983;i:1089-90.

2 Sutor A, Dagres N, Niederhoff H. Late form of vitamin K deficiency bleeding in Germany. Klin Pädiatr 1995;207:89-97.

3 Barton JS, Tripp JH, McNinch AW. Neonatal vitamin K prophylaxis in the British Isles: current practice and trends. BMF 1995;310:632-3.

4 Tripp J, Cornellissen M, Loughnan P, McNinch A, Schubiger G, von Kries R. Suggested protocol for the reporting of prospective studies of vitamin $\mathrm{K}$ deficiency bleeding (previous called hemorrhagic disease of the newbleeding (previous called hemorrhagic disease of the newinfancy. Stuttgart: Schattauer Verlag, 1995: 395-401.

5 Tin W, Fritz S, Wariyar U, Hey E. Outcome of very preterm birth: children reviewed with ease at 2 years differ from birth: children reviewed with ease at 2 years differ from
those only followed up with difficulty. Arch Dis Child Fetal those only followed up with

6 Parker L, Cole M, Craft AW, Hey EN. Neonatal vitamin K administration and childhood cancer in the north of England: retrospective case-control study. BMF 1998;316:189-93.

7 Golding J, Birmingham $\mathrm{K}$, Greenwood R, Mott $M$. Intramuscular vitamin $\mathrm{K}$ and childhood cancer. $B M \mathcal{F}$ 1992;305:341-6.

8 Chief Medical Officer. Prophylaxis against vitamin $K$ deficiency bleeding in infants. PL/CMO(92)20. London: deficiency bleeding in infants.

9 Department of Health and Social Security. Report on health and social subjects. No 18. Artificial feeds for the young infant. London: HMSO. 1980:33-40. 
10 British Paediatrics Association. Vitamin $K$ prophylaxis in infancy. Report of an Expert Committee. London: British Paediatric Association, 1992 .

11 Health Visitors' Association. Administration of vitamin $K$. London: Health Visitors' Association, 1992. (Centre circular CS/93/21)

12 Department of Health and Social Security. Report on health and social subjects. No 20. Present day practice in infant feeding: 1980. London: HMSO, 1980:20-1.

13 Department of Health and Social Security. Report on health and social subjects. No 32. Present day practice in infant feeding: third report. London: HMSO, 1988:50, 65.

14 Anonymous. Which vitamin K preparation for the newborn? Drug Ther Bull 1998;36:17-9.

15 Von Kries R. Neonatal vitamin K prophylaxis: the Gordian knot still awaits untying. BMF 1998;316:161-2.

16 Chief Medical Officer. Vitamin $K$ for newborn babies. PL/CMO/98/3. London: Department of Health, 1998.

17 Von Kries R, Göbel U, Hachmeister A., Kaletsch U, Michaelis J. Vitamin K and childhood cancer: a population Michaelis J. Vitamin K and childhood cancer: a pop
based case-control study. BMf 1996;313:199-203.

18 Ansell P, Bull D, Roman E. Childhood leukaemia and intramur vitamin K: findings from a case-control study. muscular vitamin K:

19 McKinney PA, Jaszczak E, Findlay E, Smith K. Casecontrol study of childhood leukaemia and cancer in Scotland: findings for neonatal intramuscular vitamin $\mathrm{K} . B M f$ 1998;316:173-9.

20 Passmore SJ, Draper G, Brownbill P, Kroll M. Case-control studies and relation between childhood cancer and neonatal vitamin K administration. BMf 1998;316:178-84.

21 Anonymous. Vitamin K and the newborn. [Editorial.] Lancet 1978;i: $775-7$

22 Lehmann J. Vitamin K as a prophylactic in 13,000 infants. Lancet 1994;i:493-4

23 Committee on Nutrition, American Academy of Pediatrics. Vitamin $\mathrm{K}$ compounds and the water-soluble analogues. Pediatrics 1961;28:501-7.

24 Dunn PM. Vitamin K for all newborn babies. Lancet 1982;ii:770.

25 Hanawa Y, Maki M, Murata B, et al. The second nation-wide survey in Japan of vitamin $\mathrm{K}$ deficiency in nation-wide survey in Japan of vitam
infancy. Eur $\mathcal{F}$ Pediatr 1988;147:472-7.

26 McNinch AW, Tripp JH. Haemorrhagic disease of the newborn in the British Isles: two year prospective study. $B M Y$ 1991;303:1105-9.

27 von Kries R, Göbel U. Vitamin K prophylaxis and vitamin K deficiency bleeding (VKDB) in early infancy. Acta Paediatr 1992;81:655-7.

28 Tönz O, Schubiger G. Neonatale vitamin-K-prophylaxe und vitamin-K-mangelblutungen in der Schweiz 1986-88. Schweiz Med Wschr 1988;118:1747-52.

29 Ekelund H. Late haemorrhagic disease in Sweden 1987-89. Acta Paediatr Scand 1991;80:966-8.
30 Nørgaard Hansen K, Ebbesen R. Neonatal vitamin K prophylaxis in Denmark: three years' experience with oral administration during the first three months of life compared with one oral diatr 1996;85:1137-9.

31 Cornelissen M, von Kries R, Loughnan P, Schubiger G. Prevention of vitamin $\mathrm{K}$ deficiency bleeding: efficacy of
different multiple oral dose schedules of vitamin K. Eur $\mathcal{F}$ different multiple oral dose

32 Loughnan PM, McDougall PN. Does intramuscular vitamin $\mathrm{K}_{1}$ act as an unintended depot preparation? $\mathrm{F} \mathrm{Pae}-$ diatr Child Health 1996;32:251-4

33 Baenziger O, Braegger CP, Fanconi S. Oral vitamin K prophylaxis for newborn infants: safe enough? Lancet 1996;348:1456

34 Greer FR, Marshall SP, Severson RR, et al. A new mixed micellar preparation for oral vitamin $\mathrm{K}$ prophylaxis: randomised controlled comparison with an intramuscular formulation in breast fed infants. Arch Dis Child 1998;79:300-5.

35 Schubiger G, Grüter J, Shearer MJ. Plasma vitamin $\mathrm{K}_{1}$ and PIVKA-II after oral administration of mixed micellar or cremophor EL-solubilized preparations of vitamin $\mathrm{K}_{1}$ to normal breast-fed newborns. $尹$ Pediatr Gastroenterol Nutr 1997;24:280-4.

36 Schubiger G, Tünz O, Gröter J, Shearer MJ. Vitamin K1 concentration in breast-fed neonates after oral and intramuscular administration of a single dose of a new mixed-micellar preparation of phylloquinone. If Pediatr Gastroenterol Nutr 1993;16:435-9.

37 Croucher C, Azzopardi D. Compliance with recommendations for giving vitamin $\mathrm{K}$ to newborn infants. $B M \mathcal{F}$ 1994;308:894-5.

38 Doran O, Austin NC, Taylor BJ. Vitamin K administration in neonates: survey of compliance with recommended practices in the Dunedin area. NZ Med f 1995;108:337-9.

39 Tripp JH, McNinch AW. The vitamin K debacle: cut the Gordian knot but first do no harm. Arch Dis Child Gordian knot

40 Cornelissen EAM, Hirasing RA, Monnens LAH. Prevalentie van bloedingen door vitamin K-tekort in Nederland, 1992-1994. Ned Tijdschr Geneeskd 1996;140:935-9.

41 Zipursky A. Prevention of vitamin K deficiency bleeding in newborns. Br 7 Haematol 1999;104:430-7.

42 Nishiguchi T, Saga K, Sumimoto K, Okada K, Terao T. Vitamin $\mathrm{K}$ prophylaxis to prevent vitamin $\mathrm{K}$ deficient intracranial haemorrhage in Shizuoko prefecture. $\mathrm{Br} F$ Obstet Gynaecol 1996;103:1078-84.

43 Greer FR, Marshall SP, Foley AL, Suttie JW. Improving the vitamin $\mathrm{K}$ status of breastfeeding infants with maternal vitamin K supplements. Pediatrics 1997;99:88-92.

44 Bolisetty S, Gupta JM, Graham GG, Salonikas C, Naidoo D. Vitamin $\mathrm{K}$ in preterm breastmilk with maternal supplementation. Acta Paediatr 1998;87:960-2. 